\title{
Photobiomodulation Therapy Decreases Oxidative Stress in the Lung Tissue after Formaldehyde Exposure: Role of Oxidant/Antioxidant Enzymes
}

\author{
Rodrigo Silva Macedo, ${ }^{1}$ Mayara Peres Leal, ${ }^{1}$ Tarcio Teodoro Braga, ${ }^{2}$ Éric Diego Barioni, ${ }^{3}$ \\ Stephanie de Oliveira Duro, ${ }^{3}$ Anna Carolina Ratto Tempestini Horliana, \\ Niels Olsen Saraiva Câmara, ${ }^{2}$ Tânia Marcourakis, ${ }^{3}$ Sandra Helena Poliselli Farsky, ${ }^{3}$ \\ and Adriana Lino-dos-Santos-Franco ${ }^{1}$ \\ ${ }^{1}$ Postgraduate Program in Biophotonics Applied to Health Sciences, University Nove de Julho (UNINOVE), \\ Rua Vergueiro, 235/249 Liberdade, 01504-001 São Paulo, SP, Brazil \\ ${ }^{2}$ Department of Immunology, University of São Paulo, São Paulo, Brazil \\ ${ }^{3}$ Department of Clinical and Toxicological Analyses, Faculty of Pharmaceutical Sciences, University of São Paulo, \\ São Paulo, Brazil
}

Correspondence should be addressed to Adriana Lino-dos-Santos-Franco; alsantosfranco@gmail.com

Received 18 February 2016; Revised 28 April 2016; Accepted 4 May 2016

Academic Editor: Helen C. Steel

Copyright (C) 2016 Rodrigo Silva Macedo et al. This is an open access article distributed under the Creative Commons Attribution License, which permits unrestricted use, distribution, and reproduction in any medium, provided the original work is properly cited.

Formaldehyde is ubiquitous pollutant that induces oxidative stress in the lung. Several lung diseases have been associated with oxidative stress and their control is necessary. Photobiomodulation therapy (PBMT) has been highlighted as a promissory treatment, but its mechanisms need to be better investigated. Our objective was to evaluate the effects of PBMT on the oxidative stress generated by FA exposure. Male Wistar rats were submitted to FA exposure of $1 \%$ or vehicle (3 days) and treated or not with PBMT ( 1 and $5 \mathrm{~h}$ after each FA exposure). Rats treated only with laser were used as control. Twenty-four hours after the last FA exposure, we analyzed the effects of PBMT on the generation of nitrites and hydrogen peroxide, oxidative burst, glutathione reductase, peroxidase, S-transferase enzyme activities, the gene expression of nitric oxide, cyclooxygenase, superoxide dismutase, the catalase enzyme, and heme oxygenase-1. PBMT reduced the generation of nitrites and hydrogen peroxide and increased oxidative burst in the lung cells. A decreased level of oxidant enzymes was observed which were concomitantly related to an increased level of antioxidants. This study provides new information about the antioxidant mechanisms of PBMT in the lung and might constitute an important tool for lung disease treatment.

\section{Introduction}

Oxidative stress is characterized by the imbalance between an increased generation of reactive oxygen and nitrogen species (RONS) and a reduced antioxidant capacity. RONS are produced in high quantities by endogenous metabolisms which are represented primarily by the activation of neutrophils, the products of cyclooxygenase (COX), lipoxygenase (LOX), and nitric oxide synthases (NOS) [1-3]. At the same time,
RONS are also produced in the body through exogenous factors including formaldehyde (FA), particulate matter (PM), metals, and quinones [4-9].

We have identified oxidative stress as an important pathway in which FA exerts its toxic effects, with a disruption of the lung physiological balance between the oxidant and antioxidant systems, modulating positively with a neutrophilic lung inflammation $[9,10]$. FA is ubiquitous pollutant found in many industries, offices, and laboratories, and it is 
also emitted in the domestic ambient of homes, in things such as furniture, building materials, and chipboards, and in heating and cooking fumes [11].

Neutrophils that are activated by different biochemical mechanisms produce high quantities of RONS and inflammatory cytokines, leading to a severe destruction of the lung tissues $[12,13]$. However, the deleterious effects of RONS are neutralized naturally by the lung through the defensive antioxidant system. Among the main antioxidant sources in the lung are glutathione reductase, peroxidase, s-transferase enzymes, superoxide dismutase, the catalase enzyme, and heme oxygenase-1 [14-16].

Several lung diseases such as asthma, chronic obstructive pulmonary diseases, and lung fibrosis have been associated with oxidative stress [17-19]. Lung diseases constitute an important public health problem and the control of oxidative stress into the lung is necessary. In this context, photobiomodulation has been highlighted as a promissory treatment, because of the absence of side effects, displaying low costs, and a noninvasiveness. However, its mechanisms need to be better investigated and understood.

Some studies have evaluated the antioxidant effects of laser therapy by using different models in vivo and in vitro [20-23]. When considering the antioxidant effects of PBMT in the lung tissues, studies have reported that, in an animal experimental model, laser treatment restored the balance between the oxidant and the antioxidant mediators, raising the PPAR expression and consequently the production of HSP70 [22].

Based upon the oxidative stress that is induced by FA exposure in the lung tissues and the antioxidant effects of PBMT, we evaluated the generation of nitrites and hydrogen peroxide, oxidative burst, glutathione reductase, peroxidase, s-transferase enzyme activities, the gene expression of nitric oxide, cyclooxygenase, superoxide dismutase, the catalase enzyme, and heme oxygenase-1. Thus, this study may provide information about the antioxidant mechanisms of PBMT in lung diseases.

\section{Materials and Methods}

The experiments were approved by the Committee on the Ethics of Animal Experiments of the University of Nove de Julho (CoEP-UNINOVE, Permit Number: AN0029.2014).

2.1. Animals. Male 2-month-old Wistar rats (40) were obtained from the University Nove de Julho and maintained in a light and temperature-controlled room (12/12-hour lightdark cycle, $21 \pm 2^{\circ} \mathrm{C}$ ), with free access to food and water.

\subsection{Formaldehyde (FA) Exposure. Group of rats (5/chamber)} were exposed to FA inhalation $(1 \%, 90 \mathrm{~min} /$ day $)$ or vehicle (distilled water) for 3 consecutive days. Thus, we utilized a standard glass chamber $(20 \mathrm{~L})$ coupled to an ultrasonic nebuliser device (Icel ${ }^{\oplus}$, Brazil) which produces an aerosol with particles between 0.5 and 1 micron to generate a constant airstream in an aqueous solution of formalin $[9,10,24]$.
2.3. Photobiomodulation Therapy. According to Miranda da Silva et al. [25], rats received infrared laser (CW Diode LaserMMOptics, São Paulo, Brazil) 1 and $5 \mathrm{~h}$ after each FA or vehicle inhalation. The irradiation was performed directly in the skin in nine points of respiratory tract (3 points in the trachea and 3 points in the right and left lung lobes). After $24 \mathrm{~h}$ of last FA exposure the analyses were performed. We used the following parameters: output power of $30 \mathrm{~mW}, 660 \mathrm{~nm}$ wavelength, $60 \mathrm{~s} /$ point, and spot size of $0.14 \mathrm{~cm}^{2}$, resulting in an irradiance of $210 \mathrm{~mW} / \mathrm{cm}^{2}$ and radiant exposure of $12.86 \mathrm{~J} / \mathrm{cm}^{2}$. The optical power was calibrated using a Newport $1835 \mathrm{C}$ multifunction optical power meter (Equipland, Oklahoma Road, Sao Jose, CA, USA). The laser power was monitored during laser irradiation by collecting laser light with a partial reflection (4\%) mirror. The laser irradiation dose was set at $1.8 \mathrm{~J}$ for $1 \mathrm{~min}$ [24-28].

2.4. Experimental Groups. The rats were assigned into 4 experimental groups: $\mathrm{N}$, nonmanipulated rats; FA, identified as rats submitted to FA inhalation; L, identified as rats treated only with laser; and FA $+\mathrm{L}$, identified as rats subjected to FA inhalation and treated with laser. The rats were killed by sectioning the abdominal aorta under deep anaesthesia with ketamine-xylazine by intraperitoneal route $(100 \mathrm{mg} / \mathrm{kg}$ and $20 \mathrm{mg} / \mathrm{kg}$, resp.) $24 \mathrm{~h}$ after the last FA inhalation.

2.5. Quantification of Nitrites in the Supernatant of Bronchoalveolar Lavage (BAL). The concentration of nitrites $\left(\mathrm{NO}_{2}\right)$ was determined in the BAL supernatants samples. Nitrites levels were quantified according to the Griess method. The optical density $(540 \mathrm{~nm})$ was recorded using a microplate reader (Bio-Tek Instr., USA) and the nitrites levels were obtained using a standard curve of $\mathrm{NaNO}_{2}(5-60 \mu \mathrm{M})$.

2.6. Quantification of Hydrogen Peroxide in the Bronchoalveolar Lavage (BAL) Cell Suspension. The hydrogen peroxide levels were quantified in sample of BAL cells. The BAL cell suspension $\left(1 \times 10^{5}\right.$ cells $/ \mathrm{mL}$ in phenol red solution) was stimulate with PMA (10 ng/well) and incubated at $37^{\circ} \mathrm{C}, 5 \% \mathrm{CO}_{2}$ for 1 hour. After this time, the reaction was stopped by the addition of $10 \mu \mathrm{L}$ of $\mathrm{NaOH} 1 \mathrm{~N}$. The optical density $(620 \mathrm{~nm})$ was recorded using a microplate reader (Bio-Tek Instr., USA) and the hydrogen peroxide levels were obtained using a standard curve of $\mathrm{H}_{2} \mathrm{O}_{2}(0-200 \mathrm{nM})$ and expressed in $\%$ $\mathrm{H}_{2} \mathrm{O}_{2} / 1 \times 10^{4}$ cells.

2.7. Determination of Gene Expression of Oxidants and Antioxidants Enzymes in the Lung Tissue. Lung samples were snap-frozen in liquid nitrogen. The total RNA was isolated from lung tissue using Trizol Reagent (Invitrogen, Carlsbad, CA) according to Invitrogen. RNA concentrations were determined by spectrophotometer absorbance readings at $260 \mathrm{~nm}$. First-strand cDNAs were synthesized using the MML-V reverse transcriptase (Promega, Madison, WI). RTPCR was performed using the SYBR Green real-time PCR assay (Applied Biosystem, USA) for the following molecules: hypoxanthine guanine phosphoribosyl transferase (HPRT) (sense) $5^{\prime}$-CTC ATG GAC TGA TTA TGG ACA GGA C-3' 
and (antisense) $5^{\prime}$-GCA GGT CAG CAA AGA ACT TAT AGC C-3'; iNOS (sense) $5^{\prime}$-AGT GAG GAG CAG GTT GAG GA- $3^{\prime}$ and (antisense) $5^{\prime}$-GCT GTA ACT CTT CTG GGT GT-3'. RT-PCR was performed using the TaqMan real-time PCR assay (Applied Biosystem, USA) for the following molecules: COX-1 (Rn00566881_m1*), COX-2 $\left(\mathrm{Rn} 01483828 \_\mathrm{ml}^{*}\right), \quad$ SOD-1 $\left(\mathrm{Rn} 00566938 \_\mathrm{ml}^{*}\right)$, SOD2 (Rn00690587_g1 $\left.{ }^{*}\right)$, and catalase $\left(\mathrm{Rn} 00560930 \_\mathrm{m1} 1^{*}\right)$. Cycling conditions were as follows: $10 \mathrm{~min}$ at $95^{\circ} \mathrm{C}$ followed by 45 cycles at $20 \mathrm{~s}$ each at $95^{\circ} \mathrm{C}, 20 \mathrm{~s}$ at $58^{\circ} \mathrm{C}$, and $20 \mathrm{~s}$ at $72^{\circ} \mathrm{C}$. Analysis was performed using Sequence Detection Software 1.9 (SDS), and mRNA expression was normalized to HPRT expression.

\subsection{Quantification of Enzymatic Activities of Glutathione} Peroxidase, Reductase, and S-Transferase. Glutathione peroxidase (GPx) activity was determined using tert-butylhydroperoxide as the substrate, and the formation of oxidized glutathione (GSSG) was indirectly monitored through NAPDH consumption ( $5 \mathrm{~min}$, wavelength of $340 \mathrm{~nm}$ ). Glutathione reductase (GR) activity was determined by the reduction of GSSG to GSH measured through NADPH consumption, which was monitored spectrophotometrically $(10 \mathrm{~min}$, wavelength of $340 \mathrm{~nm}, 37^{\circ} \mathrm{C}$ ). Glutathione S-transferase (GST) activity was determined by measuring the conjugation of 1-chloro-2,4-dinitrobenzene (CDNB) with reduced glutathione. The formation of the complex was monitored spectrophotometrically ( $5 \mathrm{~min}$, wavelength of $340 \mathrm{~nm}, 25^{\circ} \mathrm{C}$ ). The GPx, GR, and GST assays were performed in a Power Wave $\times 340$ spectrophotometer (Bio-Tek Instruments INC, software KC4 v3.0).

2.9. Evaluation of Oxidative Burst in the Bronchoalveolar Lavage (BAL) Cells. Quantification of oxidative burst was performed using BAL total cells $\left(2 \times 10^{5}\right.$ cells/well $)$ estimated by means of $2^{\prime}, 7^{\prime}$-dichlorofluorescin diacetate (DCFH-DA) fluorescence cells. Direct measurement of the mean fluorescence recorded on green channel was recorded as oxidative burst. A flow cytometer (FACS Calibur, Becton Dickinson Immunocytometry Systems, San Jose, CA, USA) interfaced with a Macintosh G4 computer was used. Data from 10,000 events were collected in list mode and analyzed in Cell Quest (Becton Dickinson Immunocytometry Systems). Fluorescence data were plotted on log scale. Green fluorescence from DCFH was measured at $530 \pm 30 \mathrm{~nm}$ (FL1 detector).

2.10. Statistical Analysis. The statistical analysis was performed using the GraphPad Prism software (GraphPad Software, Inc.). The normality test was performed using Kolmogorov-Smirnov test. Since the data were parametric, we used one-way ANOVA followed by Student's NewmanKeuls. Differences were considered significant when $P<$ 0.05 .

\section{Results}

3.1. Photobiomodulation Therapy Reduced the Generation of Hydrogen Peroxide $\left(\mathrm{H}_{2} \mathrm{O}_{2}\right)$ and Nitrites $\left(\mathrm{NO}_{2}\right)$ Induced by FA Exposure in the Lung. To investigate the effects of PBMT on generation of RONS in the lung tissue, we quantified the $\mathrm{H}_{2} \mathrm{O}_{2}$ and $\mathrm{NO}_{2}$ in the bronchoalveolar lavage. Data of Figure 1 showed that treatment with laser reduced the levels of $\mathrm{H}_{2} \mathrm{O}_{2}$ (a) as well as $\mathrm{NO}_{2}$ (b) when compared to nontreated group (FA group) and did not differ from nonmanipulated and laser groups ( $\mathrm{N}$ and $\mathrm{L}$ groups). We can also observe that FA exposure increased the generation of $\mathrm{NO}_{2}$ and $\mathrm{H}_{2} \mathrm{O}_{2}$ in relation to basal $\mathrm{N}$ and $\mathrm{L}$ groups.

3.2. Photobiomodulation Therapy Increased the Oxidative Burst in the Lung. In order to investigate the effects of PBMT on the functional state of BAL cells, we evaluated the oxidative burst. Figures 2(a) and 2(b) showed that the treatment with laser increased the oxidative burst in BAL cells when compared to the FA, N, and L groups.

3.3. Photobiomodulation Therapy Reduced the Gene Expression of Nitric Oxide Synthase ( $i N O S$ and cNOS) and Cyclooxygenase (COX-2) Induced by FA Exposure in the Lung. In order to understand the possible mechanism involved in reactive oxygen and nitrogen species (RONS) after PBMT, we investigated important enzymes that generate RONS. Figure 3(a) showed that PBMT reduced the gene expression of COX-2 when compared to the N, L, and FA groups. No differences were observed between $\mathrm{FA}, \mathrm{L}$, and $\mathrm{N}$ groups.

In Figures 3(b) and 3(c), we can observe that PBMT decreased the gene expression of cNOS and iNOS, respectively, when compared to the FA group and did not differ from $\mathrm{L}$ and $\mathrm{N}$ groups. We also showed that $\mathrm{FA}$ exposure increased the gene expression of both enzymes (cNOS and iNOS) in relation to nonmanipulated rats ( $\mathrm{N}$ group) and rats treated only with laser (L group).

3.4. Photobiomodulation Therapy Increased the Gene Expression of Superoxide Dismutase (SOD-1 and SOD-2) and Heme Oxygenase-1 (HO-1) without Changing Catalase after FA Exposure in the Lung. We investigated the involvement of PBMT in the gene expression of antioxidant enzymes. Figure 4(a) showed that PBMT increased the gene expression of SOD-1 when compared to the FA, L, and N groups. On the other hand, in Figure 4(b) we showed that no differences were observed in the gene expression of catalase when rats were treated with laser (FA + L group). We also showed that FA exposure increased the gene expression of catalase in relation to control groups ( $\mathrm{N}$ and $\mathrm{L}$ ).

In Figure 4(c) we can observe that PBMT increased the gene expression of $\mathrm{HO}-1$ when compared to the $\mathrm{FA}, \mathrm{L}$, and $\mathrm{N}$ groups. We also observed that FA exposure did not induce alteration in the expression of HO-1 in relation to control groups ( $\mathrm{N}$ and $\mathrm{L}$ ).

3.5. Photobiomodulation Therapy Increased the Activity of Glutathione S-Transferase (GST) and Peroxidase (GPX) without Changing Glutathione Reductase (GR) after FA Exposure in the Lung. We also investigated the involvement of PBMT in the activity of glutathione enzymes that exert an important protection of oxidant species in the lung tissue. Figures 5(a) and 5(c) showed that PBMT increased the activity of GST and GPX, respectively, when compared to the FA, L, and N 


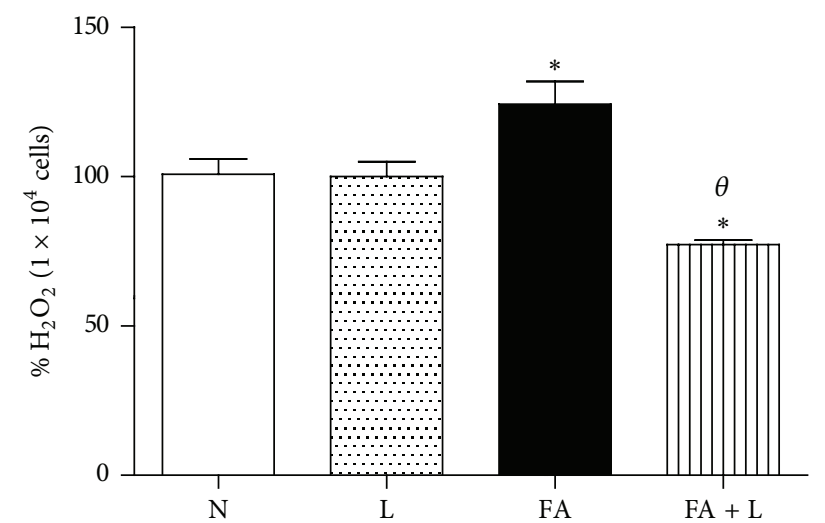

(a)

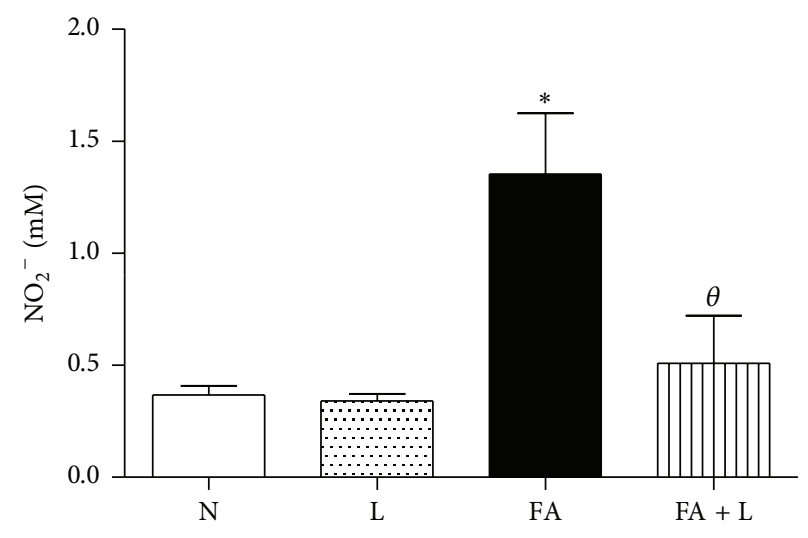

(b)

Figure 1: Photobiomodulation therapy reduces generation of $\mathrm{H}_{2} \mathrm{O}_{2}$ and $\mathrm{NO}_{2}$ after FA exposure in the lung. Group of rats was exposed or not to FA inhalation (1\%, $90 \mathrm{~min} /$ day, 3 days) and treated or not with laser ( $30 \mathrm{~mW}, 1.8 \mathrm{~J}, 60 \mathrm{~s} /$ point, total $540 \mathrm{~s}, 1$ and $5 \mathrm{~h}$ after each FA inhalation). In parallel, group of rats were treated only with laser and nonmanipulated rats were used to obtain basal parameters. The quantification of $\mathrm{H}_{2} \mathrm{O}_{2}$ and $\mathrm{NO}_{2}(\mathrm{a}, \mathrm{b})$ was determined $24 \mathrm{~h}$ after the last FA inhalation. Data mean \pm SEM of 6 animals per group. ${ }^{*} P<0.05$ in relation to $\mathrm{N}$ and $\mathrm{L}$ groups; ${ }^{\theta} \mathrm{P}<0.05$ in relation to FA group.

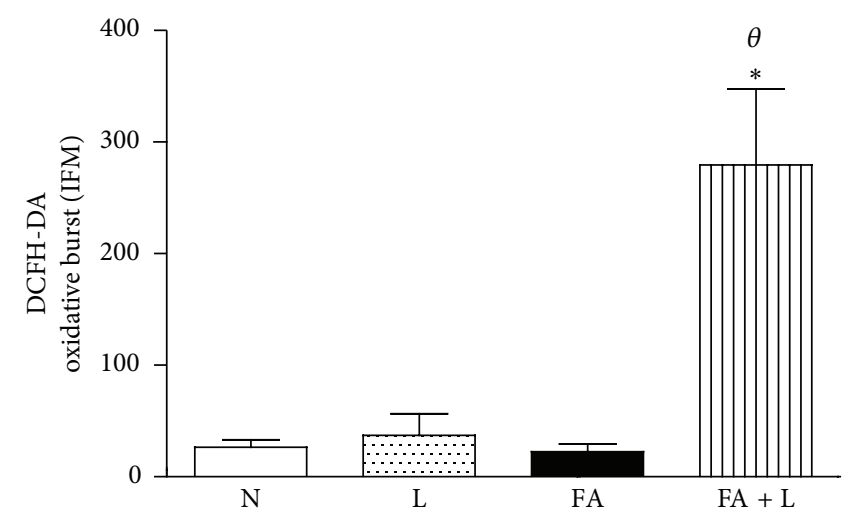

(a)
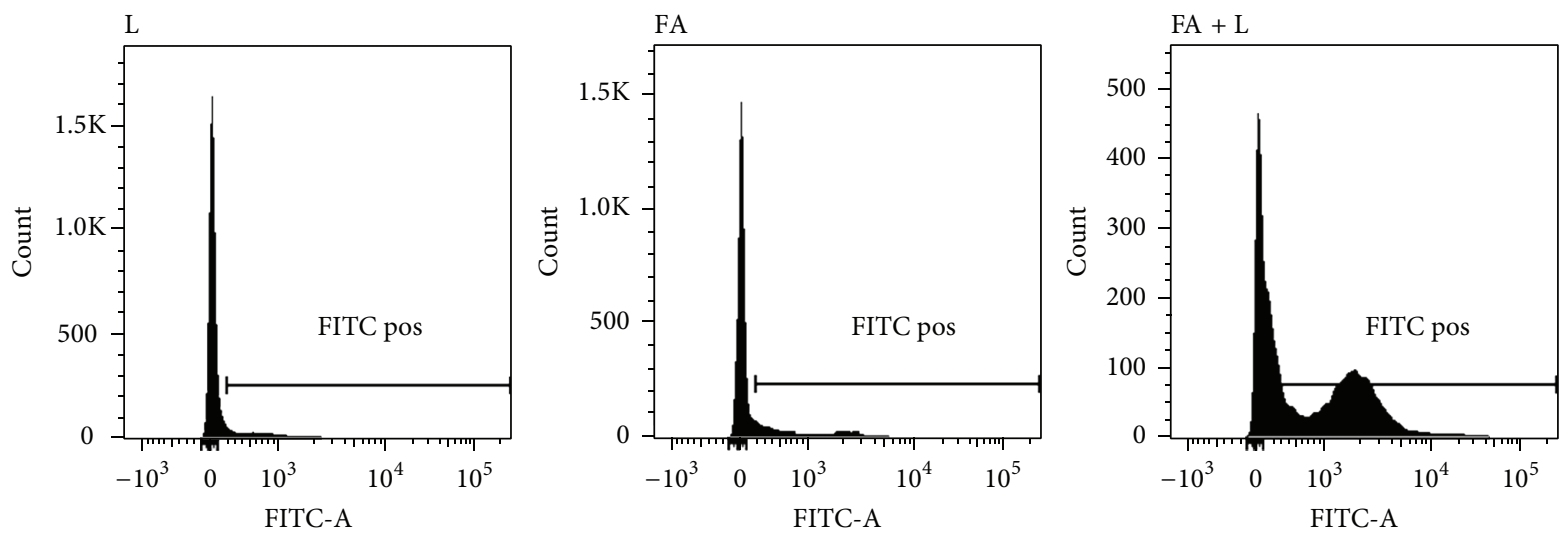

(b)

Figure 2: Photobiomodulation therapy increases oxidative burst in the lung. Group of rats was exposed to FA inhalation (1\%, 90 min/day, 3 days) and treated or not with LLLT ( $30 \mathrm{~mW}, 1.8 \mathrm{~J}, 60 \mathrm{~s} /$ point, total $540 \mathrm{~s}, 1$ and $5 \mathrm{~h}$ after each FA inhalation). In parallel, group of rats were treated only with laser and nonmanipulated rats were used to obtain basal parameters. The oxidative burst was determined $24 \mathrm{~h}$ after the last FA inhalation. Data mean \pm SEM of 6 animals per group. ${ }^{*} P<0.05$ in relation to $\mathrm{N}$ and $\mathrm{L}$ groups; ${ }^{\theta} \mathrm{P}<0.05$ in relation to FA group. 


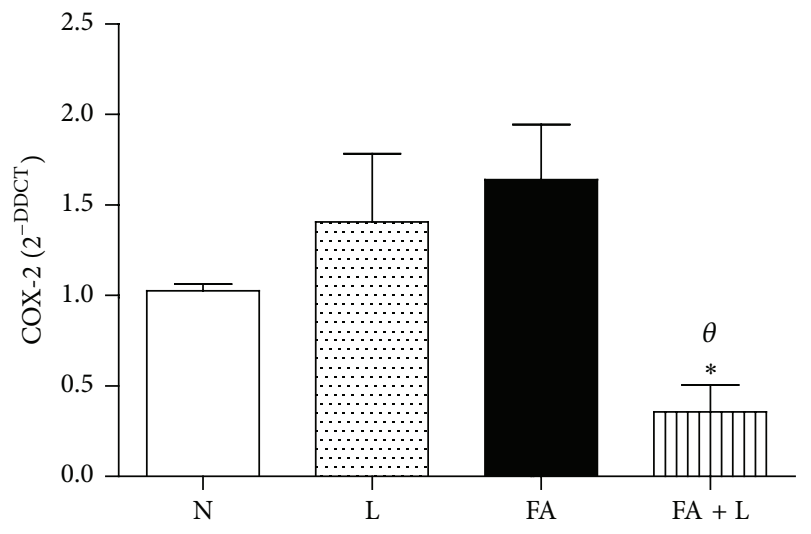

(a)

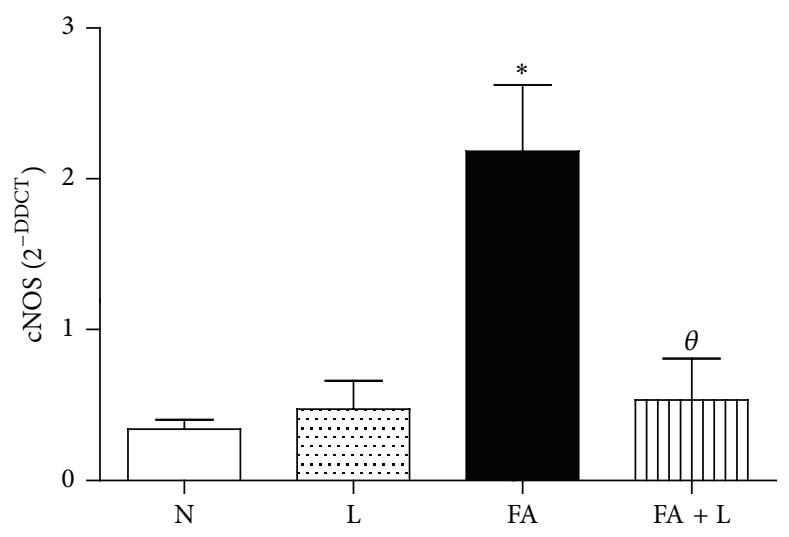

(b)

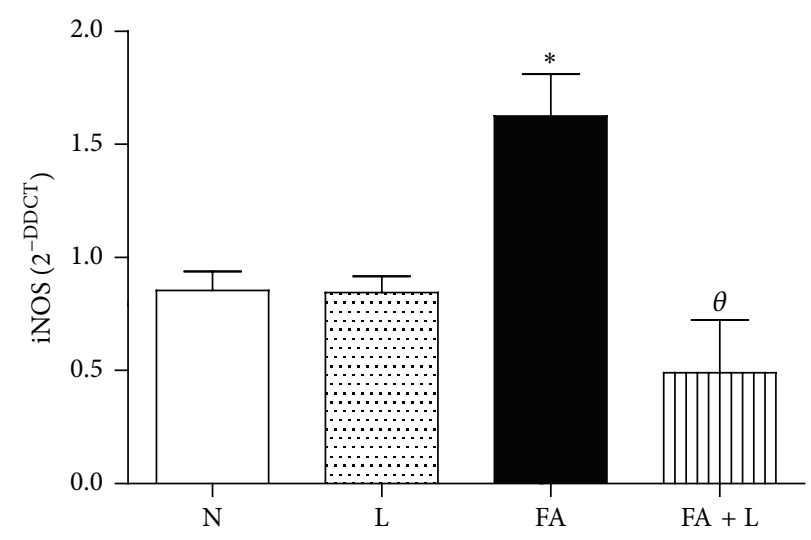

(c)

Figure 3: Photobiomodulation therapy decreases oxidant enzymes after FA exposure in the lung. Group of rats was exposed to FA inhalation $(1 \%, 90 \mathrm{~min} /$ day, 3 days $)$ and treated or not with LLLT ( $30 \mathrm{~mW}, 1.8 \mathrm{~J}, 60 \mathrm{~s} /$ point, total $540 \mathrm{~s}, 1$ and $5 \mathrm{~h}$ after each FA inhalation). In parallel, group of rats were treated only with laser and nonmanipulated rats were used to obtain basal parameters. The oxidant enzymes were determined $24 \mathrm{~h}$ after the last FA inhalation. Data mean \pm SEM of 6 animals per group. ${ }^{*} P<0.05$ in relation to $\mathrm{N}$ and $\mathrm{L}$ groups; ${ }^{\theta} P<0.05$ in relation to FA group.

groups. On the other hand, PBMT did not interfere in the GR activity (Figure 5(b)).

\section{Discussion}

Photobiomodulation therapy was an effective treatment for oxidative stress that was induced by an FA exposure in the lung tissue, as it reduced the generation of $\mathrm{H}_{2} \mathrm{O}_{2}, \mathrm{NO}_{2}$, and the gene expression of oxidant enzymes that were concomitantly related to the increased gene expression of antioxidant enzymes. Photobiomodulation therapy also increased the activity of glutathione enzymes (GST and GPX) which are highly important for the protection of the lung against oxygen and nitrogen reactive species (RONS).

When considering the fact that oxidative stress is an important pathway by which FA induces a lung inflammation, we have shown here the protective effects of PBMT. As we expected, FA exposure evoked an increased generation of RONS in the cells recruited into the lung with respect to $\mathrm{H}_{2} \mathrm{O}_{2}$ and $\mathrm{NO}_{2}$, which was reversed by PBMT. These results can explain the previous results published by our group that showed a reduced lung inflammation after PBMT [25]. This is since RONS has been implicated in initiating inflammatory responses in the lungs, through the activation of transcription factors, such as the nuclear factor NF- $\kappa \mathrm{B}$, leading to an enhanced gene expression of proinflammatory mediators.

The beneficial effects of PBMT were corroborated by a determination of the oxidative burst in the BAL cells that were predominantly neutrophils. The oxidative burst exerts an important role in the killing activity by the generation of oxygen reactive species by neutrophils. An elevated oxidative burst was found after PBMT, showing that this treatment improves the capacity of neutrophils to defend the body against microorganisms, although this process generates reactive species. Thus, we must consider that reactive species exert a dual role in the organism, protecting and/or prejudicing.

PBMT reduced the generation of $\mathrm{NO}_{2}$ and $\mathrm{H}_{2} \mathrm{O}_{2}$ and simultaneously increased the oxidative burst. These data could be considered controversial if it is not taking into account that several pathways on phagocytes can generate reactive species, which are simultaneously inactivated by antioxidant enzymes. In this context, phagocytes, such as macrophages and neutrophils, generate reactive species via 


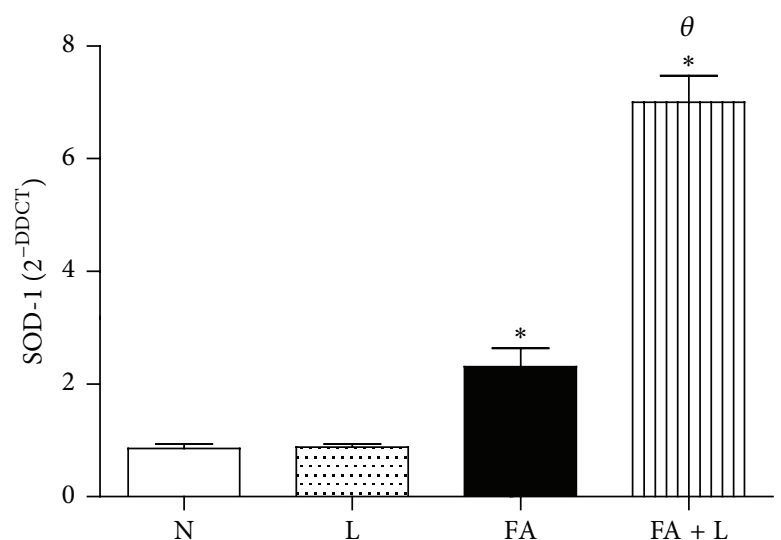

(a)

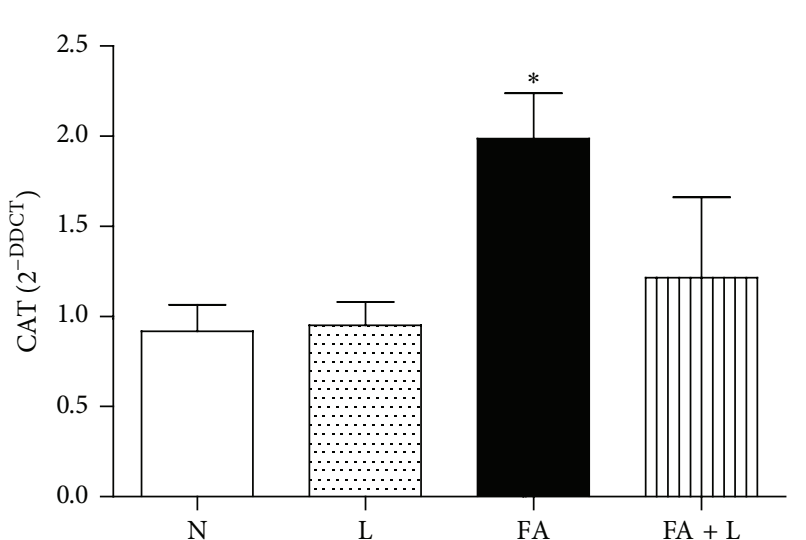

(b)

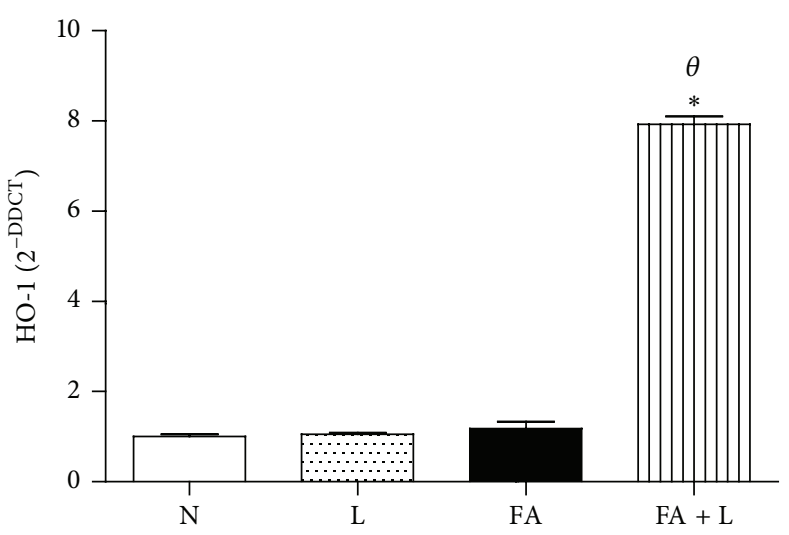

(c)

FIGURE 4: Photobiomodulation therapy increases antioxidant enzymes after FA exposure in the lung. Group of rats was exposed to FA inhalation (1\%, $90 \mathrm{~min} /$ day, 3 days) and treated or not with LLLT ( $30 \mathrm{~mW}, 1.8 \mathrm{~J}, 60 \mathrm{~s} /$ point, total $540 \mathrm{~s}, 1$ and $5 \mathrm{~h}$ after each FA inhalation). In parallel, group of rats were treated only with laser and nonmanipulated rats were used to obtain basal parameters. The antioxidant enzymes were determined $24 \mathrm{~h}$ after the last FA inhalation. Data mean \pm SEM of 6 animals per group. ${ }^{*} P<0.05$ in relation to $\mathrm{N}$ and $\mathrm{L}$ groups; ${ }^{\theta} P<0.05$ in relation to FA group.

oxidative burst, regulated by NADPH-oxidase. This latter enzyme generates superoxide radical that is subsequently converted into hypochlorous acid, a potent bactericidal agent. Thus, increased oxidative burst may be observed in reduced levels of $\mathrm{H}_{2} \mathrm{O}_{2}$. In addition, different mechanisms of defense against $\mathrm{H}_{2} \mathrm{O}_{2}$ production are available, such as glutathione peroxidase that was increased by PBMT, which contribute to reduced levels of $\mathrm{H}_{2} \mathrm{O}_{2}$. It is important to mention that our results corroborate those obtained by Dolgushin et al. [29], which showed that PBMT increased killing activity by neutrophils.

Since, in previous studies, we have shown that FA exposure causes a disruption of the physiological balance between the oxidant and antioxidant enzymes in the lung tissue, most likely by favoring the oxidant pathways and thus positively modulating the lung's inflammation [11,20], we have investigated the effects of PBMT on the gene expression of these oxidant and antioxidant enzymes in the lung tissue.

Based on previous studies, we suppose that RONS produced during FA inhalation, generated by oxidant/antioxidant enzymes imbalance in the lung tissue, might alter the metabolism of lung phagocytes, which in turn could increase the release of inflammatory mediators, as well as reactive species, amplifying the lung inflammatory response [30]. In addition, it is reasonable to admit that we analyzed enzymes in the whole lung tissue, including parenchyma, muscle cells, structural cells, and phagocytes.

Our data has shown that PBMT reversed the increased gene expression of cNOS and iNOS in the lung tissue after FA exposure. These results corroborate with the reduced $\mathrm{NO}_{2}$ released by the BAL cells. Similarly, PBMT also reduced the gene expression of COX-2 that is an important oxidant enzyme and one that generates potent inflammatory mediators including eicosanoids. We can infer this reduction in the COX, as well as in the NOS, and where this is caused by a PBMT, these results might be responsible, at least in part, for the decreased generation of oxidative species released during an FA exposure and culminating in a reduced lung inflammation, as noted previously [25].

In the literature few studies showed the PBMT effects in model of lung diseases [22, 25-28]. Almost the works showed the anti-inflammatory and antioxidants effects of PBMT in 


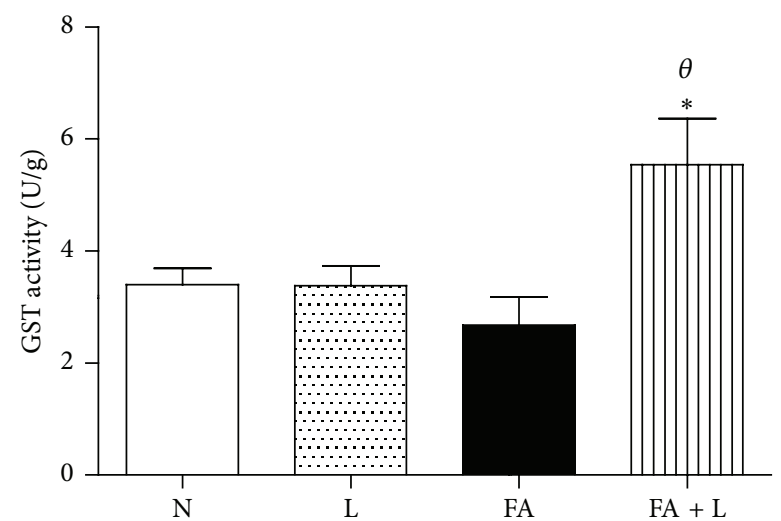

(a)

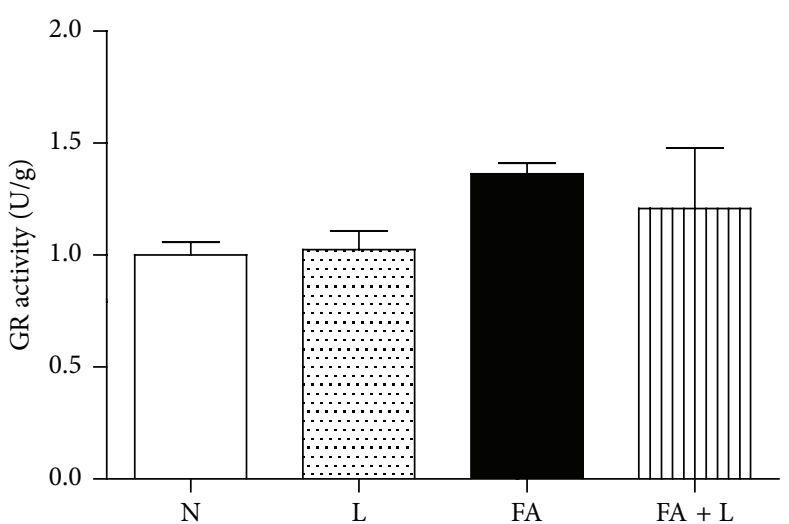

(b)

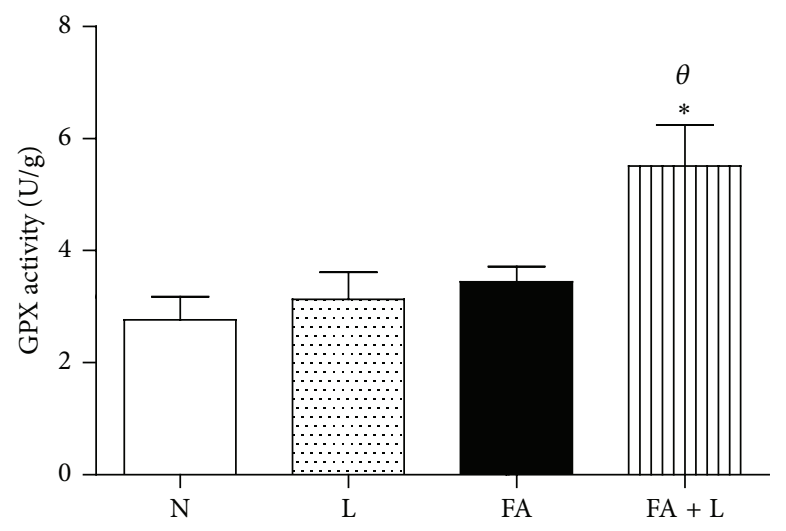

(c)

FIGURE 5: Photobiomodulation therapy increases activity of glutathione s-transferase and peroxidase enzymes after FA exposure in the lung. Group of rats was exposed to FA inhalation (1\%, $90 \mathrm{~min} /$ day, 3 days) and treated or not with LLLT (30 mW, $1.8 \mathrm{~J}, 60 \mathrm{~s} /$ point, total $540 \mathrm{~s}, 1$ and $5 \mathrm{~h}$ after each FA inhalation). In parallel, group of rats were treated only with laser and nonmanipulated rats were used to obtain basal parameters. The activities of glutathione s-transferase, reductase, and peroxidase were determined $24 \mathrm{~h}$ after the last FA inhalation. Data mean \pm SEM of 6 animals per group. ${ }^{*} P<0.05$ in relation to $\mathrm{N}$, and $\mathrm{L}$ groups; ${ }^{\theta} \mathrm{P}<0.05$ in relation to FA group.

experimental models of arthritis. Thus, studies that investigate the effects of PBMT in lung diseases are important, showing the alternative therapy without side effects.

As mentioned above, we also evaluated the antioxidant enzymes including SOD, CAT, HO-1, GPX, GR, and GST. The increased gene expression of SOD and HO-1 demonstrated the protective antioxidant mechanisms that are induced by PBMT. Thus, we can infer that the SOD and HO-1 gene expressions were augmented after PBMT as a compensatory mechanism that prevented a pulmonary tissue disease from the oxidative damage induced by FA. It is known that HO1 is a rate-limiting enzyme in heme catabolism, degrading heme to free iron, biliverdin, and carbon monoxide. SOD in turn promotes the degradation of the superoxide anion in hydrogen peroxide and it is less reactive. These products exert a cytoprotective mechanism against oxidative stress [31]. On the other hand, no differences were observed in CAT levels.

Another important antioxidant source in the lung is glutathione, which is essential for a defensive response to oxidants and inflammatory agents, by repairing the oxidized and damaged molecules and helping to regulate a variety of cellular functions [32]. Our study has found that the activities of GST and GPX were increased by PBMT. As previously mentioned, these data can explain the reduced levels of $\mathrm{H}_{2} \mathrm{O}_{2}$, since GPX is a potent antioxidant against $\mathrm{H}_{2} \mathrm{O}_{2}$.

Here we have utilized an interesting model of lung disease induced by pollution. Moreover, several lung diseases, such as asthma, a chronic obstructive pulmonary disease, and lung fibrosis, have all been associated with oxidative stress $[18,19$, 33 ] and in addition the pollution might aggravate these diseases. In this context, taking everything into account, our data has shown that PBMT might be as a promissory treatment for lung diseases mediated by oxidative stress. Additionally, this treatment is without side effects, it presents low costs, and it demonstrates a noninvasive therapy.

\section{Competing Interests}

The authors declare that there are no competing interests regarding the publication of this paper. 


\section{Acknowledgments}

This study was sponsored by Fundação de Amparo à Pesquisa do Estado de São Paulo (FAPESP). Adriana Lino-dos-SantosFranco is a Research Fellow from FAPESP (2015/00830-9).

\section{References}

[1] A. Manda-Handzlik and U. Demkow, "Neutrophils: the role of oxidative and nitrosative stress in health and disease," Advances in Experimental Medicine and Biology, vol. 857, pp. 51-60, 2015.

[2] H. R. Griffiths, I. H. K. Dias, R. S. Willetts, and A. Devitt, "Redox regulation of protein damage in plasma," Redox Biology, vol. 2, no. 1, pp. 430-435, 2014.

[3] H. L. Hsieh and C. M. Yang, "Role of redox signaling in neuroinflammation and neurodegenerative diseases," BioMed Research International, vol. 2013, Article ID 484613, 18 pages, 2013.

[4] N. D. Betancourt-Martínez, J. Jiménez-Villarreal, P. CarranzaRosales et al., "Sperm chromatin dispersion by formaldehyde in wistar rats," Genetics and Molecular Research, vol. 14, no. 3, pp. 10816-10826, 2015.

[5] B. Silva Ibrahim, C. Miranda da Silva, É. D. Barioni et al., "Formaldehyde inhalation during pregnancy abolishes the development of acute innate inflammation in offspring," Toxicology Letters, vol. 235, no. 2, pp. 147-154, 2015.

[6] H. Fukui, S. Endoh, M. Shichiri et al., "The induction of lipid peroxidation during the acute oxidative stress response induced by intratracheal instillation of fine crystalline silica particles in rats," Toxicology and Industrial Health, 2014.

[7] M. Maiellaro, M. Correa-Costa, L. B. Vitoretti et al., "Exposure to low doses of formaldehyde during pregnancy suppresses the development of allergic lung inflammation in offspring," Toxicology and Applied Pharmacology, vol. 278, no. 3, pp. 266274, 2014.

[8] L. Forchhammer, S. Loft, M. Roursgaard et al., "Expression of adhesion molecules, monocyte interactions and oxidative stress in human endothelial cells exposed to wood smoke and diesel exhaust particulate matter," Toxicology Letters, vol. 209, no. 2, pp. 121-128, 2012.

[9] A. Lino-dos-Santos-Franco, M. Correa-Costa, A. C. C. Dos Santos Durão et al., "Formaldehyde induces lung inflammation by an oxidant and antioxidant enzymes mediated mechanism in the lung tissue," Toxicology Letters, vol. 207, no. 3, pp. 278-285, 2011.

[10] A. Lino-dos-Santos-Franco, H. V. Domingos, A. P. L. D. Oliveira et al., "Differential effects of formaldehyde exposure on the cell influx and vascular permeability in a rat model of allergic lung inflammation," Toxicology Letters, vol. 197, no. 3, pp. 211-218, 2010.

[11] T. Salthammer, "Formaldehyde in the ambient atmosphere: from an indoor pollutant to an outdoor pollutant?" Angewandte Chemie-International Edition, vol. 52, no. 12, pp. 3320-3327, 2013.

[12] B. Amulic, C. Cazalet, G. L. Hayes, K. D. Metzler, and A. Zychlinsky, "Neutrophil function: from mechanisms to disease," Annual Review of Immunology, vol. 30, pp. 459-489, 2012.

[13] J. A. Marwick, D. A. Dorward, C. D. Lucas et al., “Oxygen levels determine the ability of glucocorticoids to influence neutrophil survival in inflammatory environments," Journal of Leukocyte Biology, vol. 94, no. 6, pp. 1285-1292, 2013.
[14] S. K. Biswas and I. Rahman, "Environmental toxicity, redox signaling and lung inflammation: the role of glutathione," Molecular Aspects of Medicine, vol. 30, no. 1-2, pp. 60-76, 2009.

[15] V. L. Kinnula and J. D. Crapo, "Superoxide dismutases in the lung and human lung diseases," American Journal of Respiratory and Critical Care Medicine, vol. 167, no. 12, pp. 1600-1619, 2003.

[16] R. Stocker, Y. Yamamoto, A. F. McDonagh, A. N. Glazer, and B. N. Ames, "Bilirubin is an antioxidant of possible physiological importance," Science, vol. 235, no. 4792, pp. 1043-1046, 1987.

[17] H. Lee, J. R. Park, E. J. Kim et al., "Cigarette smoke-mediated oxidative stress induces apoptosis via the MAPKs/STAT1 pathway in mouse lung fibroblasts," Toxicology letters, vol. 240, no. 1, pp. 140-148, 2016.

[18] T. A. Moore, K. K. Schmid, A. Anderson-Berry, and A. M. Berger, "Lung disease, oxidative stress, and oxygen requirements in preterm infants," Biological Research For Nursing, 2015.

[19] R.-M. Liu and L. P. Desai, "Reciprocal regulation of TGF- $\beta$ and reactive oxygen species: a perverse cycle for fibrosis," Redox Biology, vol. 6, pp. 565-577, 2015.

[20] A. C.-H. Chen, P. R. Arany, Y.-Y. Huang et al., "Low-Level laser therapy activates NF- $\kappa \mathrm{B}$ via generation of reactive oxygen species in mouse embryonic fibroblasts," PLOS ONE, vol. 6, no. 7, Article ID e22453, 2011.

[21] F. K. Ibuki, A. Simões, J. Nicolau, and F. N. Nogueira, "Laser irradiation affects enzymatic antioxidant system of streptozotocin-induced diabetic rats," Lasers in Medical Science, vol. 28, no. 3, pp. 911-918, 2013.

[22] F. M. de Lima, R. Albertini, Y. Dantas et al., "Low-level laser therapy restores the oxidative stress balance in acute lung injury induced by gut ischemia and reperfusion," Photochemistry and Photobiology, vol. 89, no. 1, pp. 179-188, 2013.

[23] M. Migliario, P. Pittarella, M. Fanuli, M. Rizzi, and F. Renò, "Laser-induced osteoblast proliferation is mediated by ROS production," Lasers in Medical Science, vol. 29, no. 4, pp. $1463-$ 1467, 2014.

[24] A. Lino dos Santos Franco, H. V. Domingos, A. S. Damazo et al., "Reduced allergic lung inflammation in rats following formaldehyde exposure: long-term effects on multiple effector systems," Toxicology, vol. 256, no. 3, pp. 157-163, 2009.

[25] C. Miranda da Silva, M. Peres Leal, R. A. Brochetti et al., "Low level laser therapy reduces the development of lung inflammation induced by formaldehyde exposure," PLOS ONE, vol. 10, no. 11, Article ID e0142816, 2015.

[26] J. P. S. Peron, A. A. de Brito, M. Pelatti et al., "Human tubalderived mesenchymal stromal cells associated with low level laser therapy significantly reduces cigarette smoke-induced COPD in C57BL/6 mice," PLoS ONE, vol. 10, no. 8, Article ID e0136942, 2015.

[27] V. R. Silva, P. Marcondes, M. Silva et al., "Low-level laser therapy inhibits bronchoconstriction, Th2 inflammation and airway remodeling in allergic asthma," Respiratory Physiology and Neurobiology, vol. 194, no. 1, pp. 37-48, 2014.

[28] F. M. de Lima, F. Aimbire, H. Miranda, R. D. P. Vieira, A. P. de Oliveira, and R. Albertini, "Low-level laser therapy attenuates the myeloperoxidase activity and inflammatory mediator generation in lung inflammation induced by gut ischemia and reperfusion: a dose-response study," Journal of Lasers in Medical Sciences, vol. 5, pp. 63-70, 2014.

[29] I. I. Dolgushin, V. A. Markova, and O. A. Gizinger, "Monitoring of the effect of low-intensity laser radiation with constant pulse generation on neutrophil granulocytes in vitro," Bulletin of 
Experimental Biology and Medicine, vol. 150, no. 2, pp. 222-224, 2010.

[30] A. Lino-dos-Santos-Franco, H. V. Domingos, A. P. Oliveira et al., "Differential effects of formaldehyde exposure on the cell influx and vascular permeability in a rat model of allergic lung inflammation," Toxicology Letters, vol. 197, no. 3, pp. 211-218, 2010.

[31] N. G. Abraham and A. Kappas, "Pharmacological and clinical aspects of heme oxygenase," Pharmacological Reviews, vol. 60, no. 1, pp. 79-127, 2008.

[32] K. Doreswamy, B. Shrilatha, T. Rajeshkumar, and Muralidhara, "Nickel-induced oxidative stress in testis of mice: evidence of DNA damage and genotoxic effects," Journal of Andrology, vol. 25, no. 6, pp. 996-1003, 2004.

[33] H. Lee, J. R. Park Kim, E. J. Kim et al., "Cigarette smokemediated oxidative stress induces apoptosis via the MAPKs/ STAT1 pathway in mouse lung fibroblasts," Toxicology Letters, vol. 240, no. 1, pp. 140-148, 2015. 


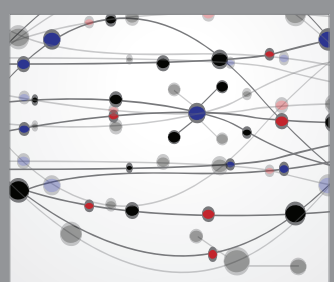

The Scientific World Journal
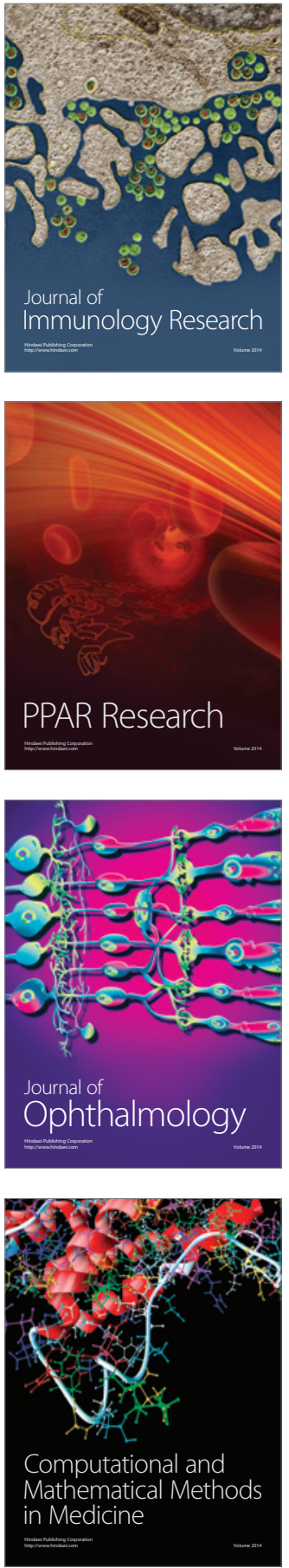

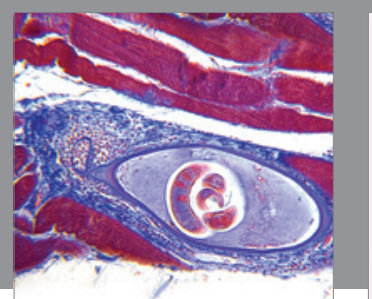

Gastroenterology Research and Practice

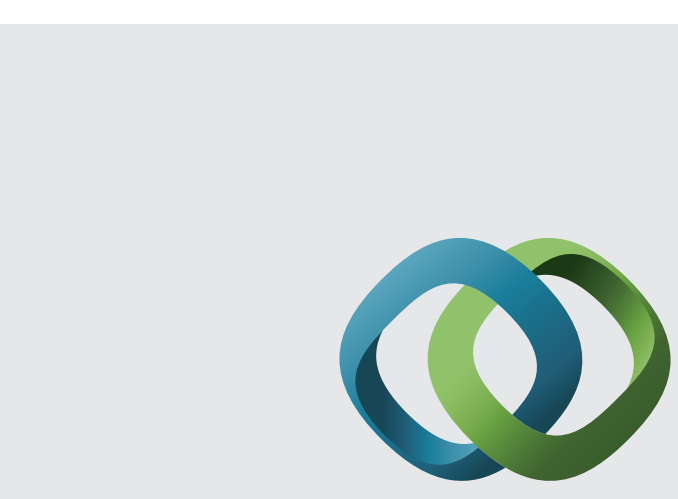

\section{Hindawi}

Submit your manuscripts at

http://www.hindawi.com
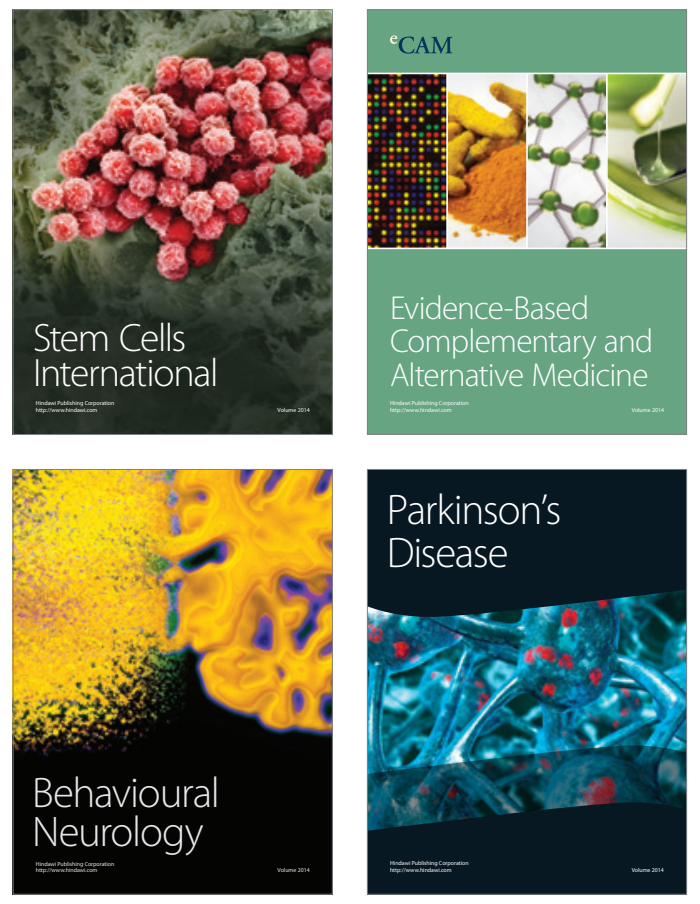
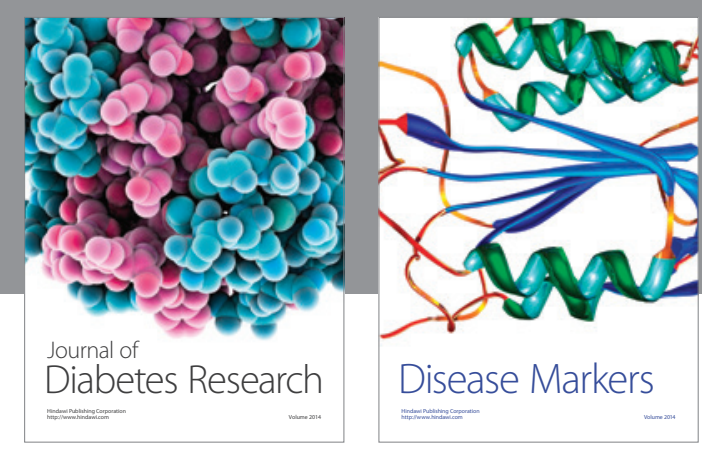

Disease Markers
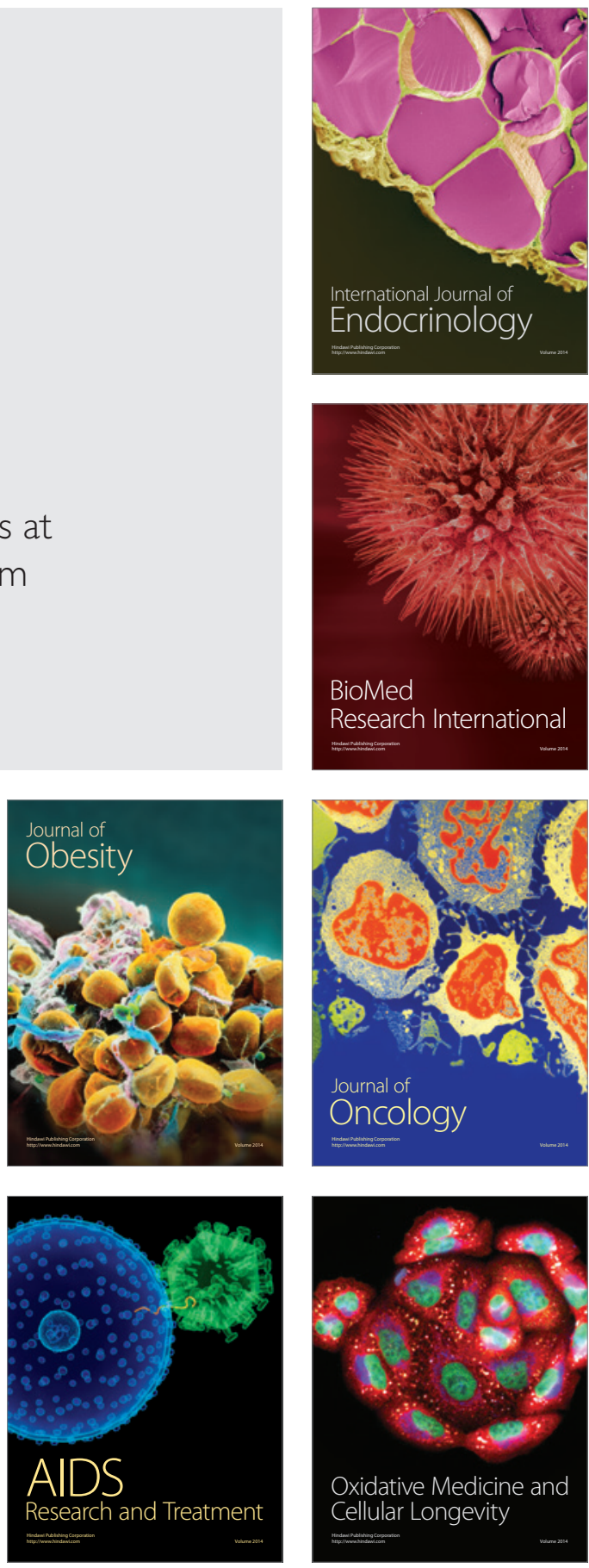